\title{
Novel approach of using a cocktail of designed bacteriophages against gut pathogenic $E$. coli for bacterial load biocontrol
}

\author{
Ahmed Sahib Abdulamir ${ }^{* *}$, Sabah AA Jassim² and Fatimah Abu Bakar ${ }^{3^{*}}$
}

\begin{abstract}
Background: This study was conducted to explore new approaches of animal biocontrol via biological control feed.

Method: White rats were subjected to 140 highly lytic designed phages specific against $E$. coli. Phages were fed via drinking water, oral injection, and vegetable capsules. Phage feeding was applied by $24 \mathrm{~h}$ feeding with $11 \mathrm{~d}$ monitoring and 20d phage feeding and monitoring. Group of rats received external pathogenic E. coli and another group did not, namely groups A and B.

Results: Phage feeding for 20d via vegetable capsules yielded the highest reduction of fecal E. coli, 3.02 and 4.62 $\log$, in rats group A and B respectively. Second best, feeding for $20 \mathrm{~d}$ via drinking water with alkali yielded 2.78 and $4.08 \mathrm{log}$ in rats groups A and B respectively. The peak reduction in E. coli output was 5-10 d after phage feeding. Phage control declined after $10^{\text {th }}$ day of feeding.

Conclusions: The use of cocktail of designed phages succeeded in suppressing flora or external $E$. coli. The phage feed biocontrol is efficient in controlling E. coli at the pre-harvest period, precisely at the $6^{\text {th }}-8^{\text {th }}$ day of phage feeding when the lowest $E$. coli output found.
\end{abstract}

Keywords: Bacteriophage, Animal feed, Biocontrol, E. coli, Bioprocessing, Phage design, Phage cocktail

\section{Background}

Escherichia coli (E. coli) is the predominant nonpathogenic facultative flora of the human and animal intestine [1]. However, several strains of E. coli have developed the ability to cause diseases in humans. Strains of $E$. coli that cause gastroenteritis in humans can be grouped into six categories: enteroaggregative (EAEC), enterohemorrhagic (EHEC), enteroinvasive (EIEC), enteropathogenic (EPEC), enterotoxigenic (ETEC), and diffuse adherent (DAEC) [1].

Among the most notorious, EHEC is a variety of E. coli that produces large quantities of one or more related potent toxins that cause severe damage to the lining of the intestine. These shiga-like toxins act on vero cells

\footnotetext{
* Correspondence: ahmsah73@yahoo.com; fatim@putra.upm.edu.my ${ }^{1}$ Microbiology Department, College of Medicine, Alnahrain University, Baghdad 14222, Iraq

${ }^{3}$ Faculty of Food Science, University Putra Malaysia, Serdang 43400, Selangor, Malaysia

Full list of author information is available at the end of the article
}

of colorectum [2]. It is transmitted to humans through contaminated food, water, and direct contact with infected people or animals [3].

The infectious dose of EHEC and other pathogenic E. coli is very low, under 100 organisms [4] which requires stringent measures to decrease $E$. coli load from animals and environment. The organism can be found on most cattle farms and it is commonly found in petting zoos and can live in the intestines of healthy cattle, deer, goats, and sheep [5]. Therefore, meat can become contaminated during and after slaughtering, and organisms can be accidentally mixed into meat when it is ground [6]. Moreover, E. coli is highly present on the cow's udders or on equipment used in milking which may get into raw milk [7]. Therefore, drinking milk or eating meat, especially ground beef that has not been cooked sufficiently to kill $E$. coli, can cause infection given that contaminated meat looks and smells normal. This problem has not yet been worked out due to the 
lack of the appropriate measures to lower, or if possible, abolish the E. coli burden from animal gut before or during slaughtering. Therefore, novel approaches of animal biocontrol against $E$. coli might be necessary to pursue, including bacteriophage-based biocontrol.

Phage biocontrol represents the application of specific phages, which are pathogens of bacteria, to selectively reduce or eliminate pathogen-susceptible organisms from specific natural environments (e.g., the bodies of humans and other animals), artificial environments (e.g., farms, factories, offices, hospitals, etc.), or even laboratory environments (e.g., to reduce streptomycete numbers on soil dilution plates $[8,9]$. The ability of phages to recognize precisely their hosts, rendered them as favorable antibacterial agents because broad-spectrum antibiotics kill target bacteria along with other beneficial bacteria present in the farm or in the organism body, say intestinal flora [10]. Many studies were applied mainly in the Soviet Union counties showed that application of phages in bacterial therapy or biocontrol is attainable in theory but practicably results were not so successful due to the lack of full coverage of target bacteria and the rapid emergence of bacterial mutations leading to complete resistance against phage infection [11-14]. Therefore, phage therapy or phage biocontrol have become unsuccessful [15] and eventually led to replacement of phage therapy with antibiotic treatment [12].

The exploitation of bacteriophages as a realistic approach to the control of pathogens has attracted considerable interest in recent years $[10,14]$ because of the emergence of antibiotic resistant bacteria. For example, calves and piglets with diarrhea due to experimentally administered pathogenic $E$. coli were cured within $8 \mathrm{~h}$ following phage administration [16]. Experimentally induced diarrhea could be prevented by spraying the litter in the calf rooms with aqueous phage suspensions or by keeping calves in uncleaned rooms previously occupied by calves whose $E$. coli infection had been treated by phage administration [17]. Hence, elimination of the pathogenic E. coli at the preharvest stage could play a significant role in preventing its introduction the food chain [18]. Bactericidal bacteriophages may provide a natural, nontoxic, feasible approach for controlling several human pathogens [11] since phages are part of both gastrointestinal and environmental ecosystems [19].

Unfortunately, the lack of techniques to counter phage sequestration, resistance, and conversion eventually led to replacement of phage therapy with antibiotic treatment [12]. However, with our exclusive knowledge of phage breeding techniques, it may be possible to circumvent the problems encountered in previous attempts to use phages as natural antimicrobial agents. In this study, a cocktail of 140 specific lytic phages, which were previously optimized and bred by non-genetic breeding techniques bacteria [IPO-UK Patent Application No. 0822068] was used in novel approaches in animal biocontrol and animal feed. White rats were used for testing the animal feed with anti-E. coli phage cocktail. The intestinal load of $E$. coli as well as experimentally inoculated human pathogenic $E$. coli were then traced by microbiological methods to estimate the phage-driven decline of the E. coli microbial load in the treated animals.

\section{Methods \\ Preparation of the anti- E. coli phage cocktail Media}

Luria broth (LB): tryptone 10 g 1-1 (HiMedia, Mumbai, India), yeast extract 5 g l-1 (HiMedia, Mumbai, India), and sodium chloride $10 \mathrm{~g} \mathrm{l-1}$ (HiMedia, Mumbai, India) at pH 7.2 were used in all the protocols. L-agar (LA), consisted of the above with the addition of $14 \mathrm{~g} \mathrm{l-1}$ agar (HiMedia, Mumbai, India) was used for culture maintenance. Bacterial dilutions from $18 \mathrm{~h} \mathrm{LB}$ cultures grown at $37^{\circ} \mathrm{C}$ were carried out in phosphate buffered saline (PBS, Oxoid, UK). For plaque assay, the 'soft layer agar' used was LB prepared in Lambda-buffer [6 mmol 1-1 Tris pH 7.2, $10 \mathrm{mmol} \mathrm{l-1} \mathrm{Mg(SO4)2.7H2O,} 50 \mu \mathrm{g}$ ml-1 gelatin (Oxoid, UK)], was supplemented with 4 g l-1 agar bacteriology No. 1 (HiMedia, Mumbai, India).

\section{Bacterial strains}

Four hundred and thirty clinical isolates of EHEC and non-EHEC E. coli were obtained from hospital inpatients (Microbiology laboratories, Hospital Serdang and Hospital Kajang in Selangor, Malaysia) including documented sporadic cases of haemorrhagic colitis, non-haemorrhagic colitis, urinary tract infections, infected wounds, vaginitis, and bacteremic cases. They were reconfirmed by using Microbact GNB 12A system (Oxoid, UK), a microtitre well-scaled chemical test. Microbact system has $100 \%$ sensitivity for identifying $E$. coli from other Enterobacteracea bacteria.

In addition, several $E$. coli reference strains were used: one EHEC NTCC 129001 and five non-EHEC (two are generic strains; ATCC 12799 and NTCC 9001, three human enteropathogenic strains (EPEC); ATCC 12810, ATCC 25922, and ATCC 35218 (zoonotic). Both E. coli clinical isolates and representative NTCC and ATCC E. coli strains were used throughout phage isolation, propagation, optimization and breeding as described here. The strains were maintained on L-agar plates and transferred bimonthly. All cultures were stored at $-20^{\circ} \mathrm{C}$ in $15 \%$ glycerol. Prior to investigation a stock culture of the bacteria was maintained on LA plate. One loopful of the bacterial strain was inoculated into a $100 \mathrm{ml}$ Erlenmeyer flask containing $10 \mathrm{ml}$ of LB and incubated for $18 \mathrm{~h}$ at $37^{\circ} \mathrm{C}$ and $90 \mathrm{rev}$ min-1 in an incubator shaker (Innova 4000, New Brunswick Scientific). For experimental tests appropriate serial dilutions were made in LB. 


\section{Bacteriophages}

Wild bacteriophages (phage) used in this study were isolated from and specifically designed for 430 clinical isolates and 6 reference strains of EHEC (http://www.sumobrain. com/patents/wipo/Methods-bacteriophage-design/WO201 0064044A1.pdf). The phage master mix was composed of 140 phages that were previously isolated, bred, and produced by 2 types of novel, under patenting breeding techniques (http://patentscope.wipo.int/search/en/WO1995 023848): chemical vertical breeding which is characterized by enhancing the lytic infective criteria of the bred phages in order to obtain optimized biokinetic potential and chemical horizontal breeding which is characterized by altering the specificity of the bred phages to be reoriented to new strains of $E$. coli leading to wider coverage of target bacteria (http://www.sumobrain.com/patents/wipo/Methods -bacteriophage-design/WO2010064044A1.pdf). This breakthrough technology opened doors for designing and optimizing unprecedented phage applications including eliminating the pathogenic EHEC and non-EHEC bacteria from food, machinery tools, and medical instruments by using high number of artificially bred specific phages. The resultant phages were mixed together forming what is called the 'phage master mix'. The phage master mix was composed of 140 highly lytic and specific bred phages.

\section{Groups of tested animals}

Two groups of albino rats, Rattus norvegicus, were subjected for phage biocontrol against E. coli. Group A, rats were fed with a phage cocktail of 140 phages without prior oral inoculation with human pathogenic E. coli. In this instance, the phage cocktail targets the naturally resident $E$. coli bacteria inside the animals' gut. Group B, rats were fed for three weeks with phage cocktail of 140 phages along with, at the same time, oral inoculation of 60 human pathogenic $\mathrm{E}$.coli isolates at concentration $10^{8}$ colony forming unit $/ \mathrm{ml}(\mathrm{CFU} / \mathrm{ml})$ in drinking water. Each inoculated $E$. coli isolate was recognized by three to four phage members of the used phage master mix bacteria [IPO-UK Patent Application No. 0822068]. As many animals act as reservoir for human pathogenic $E$. coli, group $B$ provides an opportunity to test the biocontrol effect of the used phage cocktail against human E. coli pathogens that reside in the intestine of animals (Figure 1).

The control versus phage-biocontrolled fecal output of E. coli The magnitude of $E$. coli phage control was measured in terms of $\log$ reduction (LR) of $E$. coli fecal output in tested rats. The total fecal output of $E$. coli in rats was estimated before and during the oral administration of the phage master mix in order to determine the pre-treatment level of $E$. coli as well as to determine the phage-based LR of $E$. coli. For unloaded rats with pathogenic $E$. coli, group A, the control fecal output of E. coli was measured in triplicate just before feeding the phages and was considered as the baseline from which changes of phage-driven $E$. coli output were measured in terms of LR in the same rats. For rats preloaded with pathogenic E. coli, group B, were subgrouped into two sets. The first set, rats were not subjected to phage feeding which were used to measure, in triplicate, the control fecal output of the pathogenic plus resident $E$. coli. The second set, rats were subjected to phage feeding along with external $E$. coli inoculation. This set was used to measure, in triplicate, the phage-driven reduction of fecal output of $E$. coli in comparison with the first set.

\section{Measurement of the E. coli fecal output}

The fecal output of E. coli was measured by taking $0.2 \mathrm{~g}$ of feces diluted 1:5 w/v in PBS (Oxoid, UK). Afterwards, 10 $\mathrm{ul}$ of the net, 1:10, and 1:100 dilutions of the fecal solution were spotted on MacConckey agar and were incubated overnight at $43.4 \mathrm{C}$. It is well known that $E$. coli bacteria are the only lactose fermenter enterobacteriacae that able to survive temperature of 43.4C. Next day, CFU were counted per each spot of inoculation. The concentration of fecal E. coli, in CFU/ml, was then calculated by incorporating the dilution and volume factors. Hence, E. coli bacteria were cultured selectively and then counted on daily basis.

\section{Methods of the phage feeding}

Phage feeding of rat animals was conducted via three methods. First, phage master mix was incorporated in drinking water at concentration of $10^{7} \mathrm{PFU} / \mathrm{ml}$ with/ without $6 \% \mathrm{w} / \mathrm{v}$ Sodium bicarbonate and fed to animals via the rats' water feeding bottle. In this way, rats took the phage cocktail orally every time they drink water. A group of rats was allowed to drink the phagecontaining water for only one $d$ while another group was allowed to drink the phage-containing water for 20 $\mathrm{d}$ in order to compare the phage-driven LR of fecal output of $E$. coli between the single day and continuous phage feedings. The second method of feeding of phage cocktail was achieved by injecting the phage master mix in lambda buffer at concentration of $10^{7}$ $\mathrm{PFU} / \mathrm{ml}$ directly through oral route by using rats' feeding bottles without further mixing with water. Four ml of phages suspension in lambda buffer with $6 \% \mathrm{w} / \mathrm{v}$ Sodium bicarbonate were managed to be injected orally to rats 3 times a day at $2 \mathrm{~h}$ intervals for $20 \mathrm{~d}$. The third method of phage master mix feeding was done using absorbable vegetable capsules (ZeinPharma Germany $\mathrm{GmbH}$, Germany) made of Hydroxypropyl Methylcellulose (HPMC) administered orally into the tested rats. Capsules were filled with $0.5 \mathrm{ml}$ of phage cocktail in lambda buffer, $10^{6} \mathrm{PFU} / \mathrm{ml}$ of the phage master mix. Rats were given 3 capsules a day at $2 \mathrm{~h}$ intervals for $20 \mathrm{~d}$ (Figure 1). 

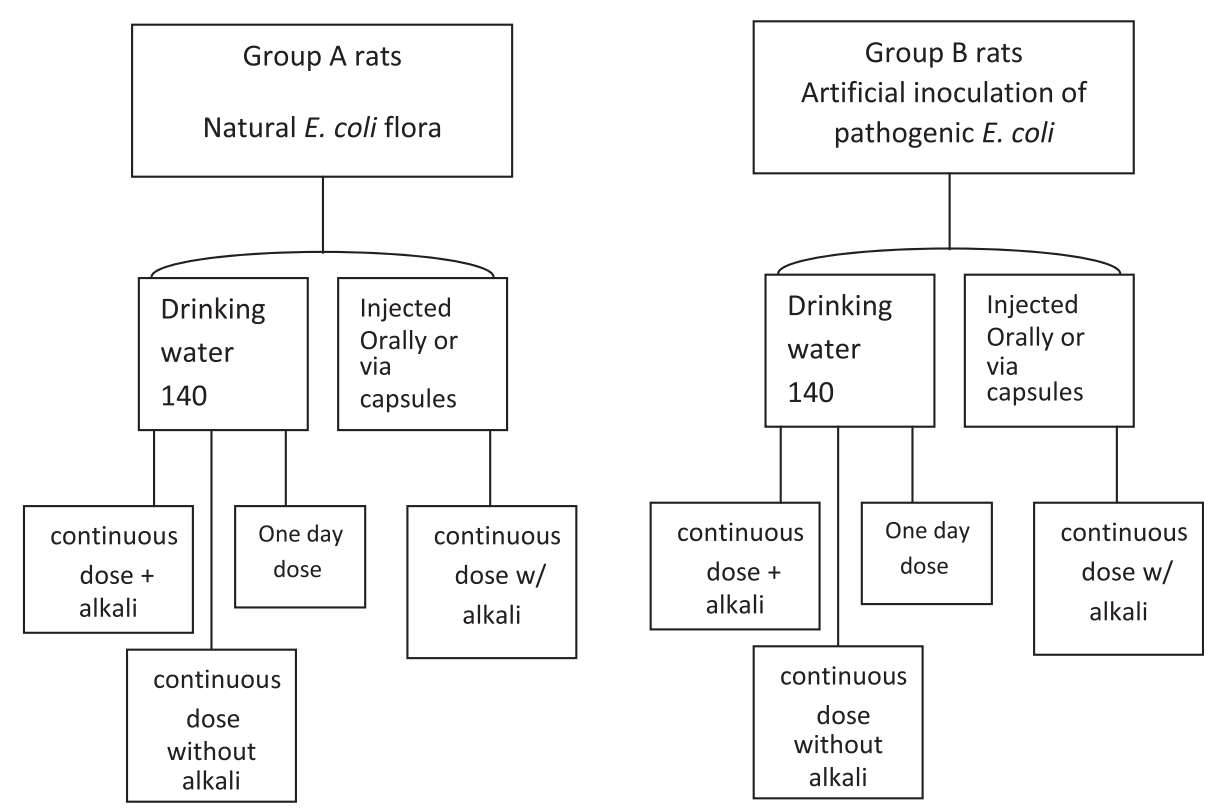

Figure 1 The outline of methodology for the phage feeding biocontrol of intestinal $E$. coli in white rats.

\section{Standardization of the phage master mix cocktail with animal feed}

Different concentrations of phage master mix were evaluated to determine the optimal concentration that results in the best controlling effects of $E$. coli bacteria in rats' intestine. The phage preparation was composed of a collection of 140 phages. Fifty ul from each bred phage were taken and collected in a $15 \mathrm{ml}$ sterile tube (Vivantis, Italy). The phage cocktail was hence composed of $6 \mathrm{ml}$. According to the method of phage administration, the final concentration of phage feed was determined. In case of phage feeding in drinkable water, $1 \mathrm{ml}$ of $10^{6-13} \mathrm{PFU} / \mathrm{ml}$ was added to $299 \mathrm{ml}$ of tap water, i.e., 1:300 dilution. Therefore, the final concentration of phage-containing water was $10^{3-10} \mathrm{PFU} / \mathrm{ml}$. The standardization procedures included administering phage cocktail via drinking water continuously for four days using different phage concentrations, $10^{3-10} \mathrm{PFU} / \mathrm{ml}$. Then, the fecal output of E. coli was evaluated by standard bacteriological methods. It was shown that the increasing phage concentration gave increasing E. coli lowering. Nevertheless, $10^{7} \mathrm{PFU} / \mathrm{ml}$ led to LR of E. coli similar to that of $10^{6} \mathrm{PFU} / \mathrm{ml}$ and slightly better than higher concentrations in both phage drinking water and oral phage injection. Therefore, phage concentration of $10^{7} \mathrm{PFU} / \mathrm{ml}$ was considered optimal for phage feeding via drinking water and lambda buffer oral injection. On the other hand, for phage containing capsules, the standardization trials showed that the optimal concentration of phage master mix was one log lower than that used in drinking water or oral injection of lambda buffer, namely $10^{6} \mathrm{PFU} / \mathrm{ml}$.

\section{Phage shedding}

Along with monitoring the effect of the phage feeding on the fecal output of $E$. coli in rat animals, the phage shedding from the animals' intestine was evaluated throughout 3 weeks of continuous phage feeding via drinking water. The aim of this step was to assess the survival of the introduced phages inside rats' intestine and assess the relationship between phage survival and its potential in lowering the intestinal E. coli. An EHEC-specific coliphage, CEH183 , was fed continuously with $6 \% \mathrm{w} / \mathrm{v}$ Sodium bicarbonate via both drinking water and oral phage injection thrice a day into rats that were previously fed with the target EHEC bacteria, EH-138, for successive 3 days in order to prepare the suitable host of the tested phage. On daily basis, $0.2 \mathrm{~g}$ of feces was diluted 1:5 w/v in PBS. Ten ul of the net, 1:10, and 1:100 dilutions of the fecal solution were then spotted on an $18 \mathrm{~h}$ bacterial lawn of EH-183. Next day, the resulted plaques were enumerated in each spot; the concentration of shed phages was then calculated in terms of PFU/ml. Therefore, the level of intestinal phage shedding was evaluated with time to probe the effect of the immunity of the tested animals on administered phages. Moreover, the level of phage shedding was essential in giving the optimal time for the peak phage replication and availability inside animals' intestine and testing whether this timing is coordinated with the optimal time of $E$. coli lowering by the effect of fed phages or not. This was important to determine the survival of phages and the effect of the animals' immunity on the phages survival. This would help determine the exact timing of the maximal phage biocontrol. 


\section{Statistical analysis}

The data was analyzed and graphics were produced using SPSS software version 12.0.0.1 as well as MS EXCEL software version 2000. Logarithmic values in terms of $\log _{10} \mathrm{CFU} / \mathrm{ml}$ and $\log _{10} \mathrm{PFU} / \mathrm{ml}$ for bacterial and phage concentrations respectively were used. The logarithmic mean, mean $\log _{10} \mathrm{CFU} / \mathrm{ml}$ or mean $\log _{10}$ $\mathrm{PFU} / \mathrm{ml}$, were calculated by averaging the individual $\log _{10} \mathrm{CFU} / \mathrm{ml}$ or $\log _{10} \mathrm{PFU} / \mathrm{ml}$ values [20]. The mean $\log$ reduction (LR) in CFU/ml was calculated by subtracting the mean $\log _{10} \mathrm{CFU} / \mathrm{ml}$ of negative control from mean $\log _{10} \mathrm{CFU} / \mathrm{ml}$ of test samples. Mean LR $\mathrm{CFU} / \mathrm{mL} \geq 1$ was considered as significant. The standard error (SE) of mean LR was calculated according to the following equation [20]:

$$
\begin{aligned}
\mathrm{SE}= & {\left[\left(\text { Variance mean } \log _{10} \mathrm{CFU} / \mathrm{mL} \text { control } \div \mathrm{N}\right)\right.} \\
& \left.+\left(\text { Variance mean } \log _{10} \mathrm{CFU} / \mathrm{mL} \text { test } \div \mathrm{N}\right)\right] \text { sq. root }
\end{aligned}
$$

Where $\mathrm{N}$ equals to sample size

\section{Results and discussion}

\section{Standardization of the administered phages}

It was found that the optimal concentration of applied phage master mix was $10^{7} \mathrm{PFU} / \mathrm{ml}$. This concentration gave results pretty similar to that of $10^{6} \mathrm{PFU} / \mathrm{ml}$ and better than higher concentrations (Table 1). On the other hand, although the phage cocktail in drinking water was refreshed daily, the phage survival in tap water was measured. It was found that significant phage decline $(>1 \log )$ started only after $6 \mathrm{~d}$ of the preparation of phage-containing drinking water. This decline in phage concentration was most likely due to phage decay. Hence, changing the phage-containing drinking water should be done every 6 days in maximum. For the sodium bicarbonate added to drinking water, it was found that $6 \%$ concentration $\mathrm{w} / \mathrm{v}$ was optimal as higher concentrations affected negatively the life span of

Table 1 Mean LR $\left(\log _{10} \mathrm{CFU} / \mathrm{ml}\right)$ of fecal output of $E$. coli in rat animals treated with different concentrations of phage master mix in drinking water

\begin{tabular}{llc}
\hline $\begin{array}{l}\text { Phage concentration } \\
\text { PFU/ml in drinking water }\end{array}$ & \multicolumn{2}{l}{ Mean LR $\left(\log _{10} \mathrm{CFU} / \mathrm{ml}\right)$} \\
\cline { 2 - 3 } & $\mathbf{2}$ days & $\mathbf{4}$ days \\
\hline $1 \times 10^{3}$ & $0 \pm 0.0$ & $1.2 \pm 0.08$ \\
$1 \times 10^{4}$ & $0.1 \pm 0.02$ & $1.2 \pm 0.1$ \\
$1 \times 10^{5}$ & $0.3 \pm 0.06$ & $1.41 \pm 0.17$ \\
$1 \times 10^{6}$ & $0.28 \pm 0.07$ & $1.36 \pm 0.07$ \\
$1 \times 10^{7}$ (optimal) & $0.6 \pm 0.04$ & $1.8 \pm 0.14$ \\
$1 \times 10^{8}$ & $0.6 \pm 0.08$ & $1.73 \pm 0.2$ \\
$1 \times 10^{9}$ & $0.5 \pm 0.04$ & $1.7 \pm 0.15$ \\
$1 \times 10^{10}$ & $0.4 \pm 0.09$ & $1.5 \pm 0.2$ \\
\hline
\end{tabular}

phage cocktail while lower concentrations have lower anti-stomach acid neutralization [data not shown].

\section{Phage biocontrol}

Group A (rats with normal intestinal E. coli flora)

Phage feeding via drinking water Single day phage feeding in drinking water:

The E. coli fecal output started to decline after day 3 from the beginning of phage feeding; the peak of LR of $E$. coli was at days four to six. The maximal phage-based LR of $E$. coli fecal output was $1.225 \log$ units, which is a significant reduction. From day seven, the phage-driven LR of $E$. coli output was started to vanish and $E$. coli count started to rise again reaching $2 . \mathrm{s} \times 10^{5} \mathrm{CFU} / \mathrm{ml}$ at day 11 which was close to the negative control concentration of the E. coli output (Table 2).

Continuous phage feeding in drinking water: The results provided evidence that intestinal $E$. coli started to decline after 3 days from the beginning of phage feeding, the peak of $E$. coli decline was day 5 to day 7 after the beginning of phage feeding. Lowest fecal output of $E$. coli was $10^{2} \mathrm{CFU} / \mathrm{ml}$ while the control load, time zero, was $2 \times 10^{4} \mathrm{CFU} / \mathrm{ml}$. The E. coli phage-driven LR was maximally $2.3 \log$ units at day 7 , which is a highly significant decline. From day 14, the phage-driven LR of E. coli output was started to vanish and $E$. coli count started to rise again reaching $1 \times 10^{4} \mathrm{CFU} / \mathrm{ml}$ at day 20 which was close to the control load of the E. coli output (Table 3).

Continuous phage feeding via drinking water with alkali: E. coli started to decline after day 2 from the beginning of phage feeding. The lowest fecal output of E. coli was $10^{2} \mathrm{CFU} / \mathrm{ml}$ at $7^{\text {th }}$ day. The maximal phage-

Table 2 LR of $E$. coli fecal output due to the effect of

\begin{tabular}{|c|c|c|}
\hline $\begin{array}{l}\text { Phage feed at } 1 \times 10^{7} \mathrm{PFU} / \mathrm{ml} \\
\text { via drinking water for one } \mathrm{d}\end{array}$ & $\begin{array}{l}\text { E. coli } \\
\text { CFU/ml }\end{array}$ & $\begin{array}{l}\text { Mean LR } \\
\left(\log _{10} \text { CFU/ml) }\right.\end{array}$ \\
\hline Time zero (control load) & $1.8 \times 10^{5}$ & - \\
\hline Day 1 & $7 \times 10^{4}$ & $0.4 \pm 0.02$ \\
\hline Day 2 & $6.3 \times 10^{4}$ & $0.45 \pm 0.08$ \\
\hline Day 3 & $6.9 \times 10^{4}$ & $0.39 \pm 0.07$ \\
\hline Day 4 & $1.3 \times 10^{4}$ & $1.11 \pm 0.12$ \\
\hline Day 5 & $1 \times 10^{4}$ & $1.22 \pm 0.18$ \\
\hline Day 6 & $1.5 \times 10^{4}$ & $1.04 \pm 0.22$ \\
\hline Day 7 & $4.7 \times 10^{4}$ & $0.55 \pm 0.1$ \\
\hline Day 8 & $1 \times 10^{5}$ & $0.22 \pm 0.08$ \\
\hline Day 9 & $2 \times 10^{5}$ & $-0.07 \pm 0.01$ \\
\hline Day 10 & $2.5 \times 10^{5}$ & $-0.17 \pm 0.06$ \\
\hline Day 11 & $2.2 \times 10^{5}$ & $-0.1 \pm 0.04$ \\
\hline
\end{tabular}
single day feeding of phage master mix 
Table 3 LR of E. coli fecal output due to the effect of continuous feeding of phage master mix for $20 \mathrm{~d}$ via drinking water

\begin{tabular}{|c|c|c|}
\hline $\begin{array}{l}\text { Phage feed at } 1 \times 10^{7} \mathrm{PFU} / \mathrm{ml} \\
\text { via drinking water for } 20 \mathrm{~d}\end{array}$ & $\begin{array}{l}\text { E. coli } \\
\text { CFU/mL }\end{array}$ & $\begin{array}{l}\text { Mean LR } \\
\left(\log _{10} \text { CFU/ml) }\right.\end{array}$ \\
\hline Time zero (control load) & $2 \times 10^{4}$ & - \\
\hline Day 1 & $2 \times 10^{4}$ & $0 \pm 0.0$ \\
\hline Day 2 & $2.4 \times 10^{4}$ & $-0.08 \pm 0.007$ \\
\hline Day 3 & $1 \times 10^{4}$ & $0.3 \pm 0.01$ \\
\hline Day 4 & $2 \times 10^{3}$ & $1 \pm 0.08$ \\
\hline Day 5 & $2 \times 10^{2}$ & $2 \pm 0.12$ \\
\hline Day 6 & $2 \times 10^{2}$ & $2 \pm 0.15$ \\
\hline Day 7 & $1 \times 10^{2}$ & $2.3 \pm 0.24$ \\
\hline Day 8 & $4 \times 10^{2}$ & $1.7 \pm 0.2$ \\
\hline Day 10 & $6 \times 10^{2}$ & $1.52 \pm 0.18$ \\
\hline Day 12 & $1 \times 10^{3}$ & $1.3 \pm 0.1$ \\
\hline Day 14 & $4.8 \times 10^{3}$ & $0.61 \pm 0.06$ \\
\hline Day 16 & $1 \times 10^{3}$ & $1.3 \pm 0.09$ \\
\hline Day 20 & $1 \times 10^{4}$ & $0.3 \pm 0.04$ \\
\hline
\end{tabular}

driven LR of $E$. coli was $2.78 \log$ units, which is a significant decline. From day 14, the phage-driven decline of E. coli output was started to vanish and $E$. coli count started to rise again reaching $3 \times 10^{4} \mathrm{CFU} / \mathrm{ml}$ at day 20 which was close to the control load of the $E$. coli fecal output (Table 4).

\section{Phage feeding via oral injection}

In this method of administration, one protocol was pursued which is continuous feeding of phages for $20 \mathrm{~d}$ with alkali because it proved to be the best protocol in the

Table 4 LR of $E$. coli fecal output due to the effect of continuous feeding of phage master mix for $\mathbf{2 0 ~ d ~ v i a ~}$ drinking water with alkali

\begin{tabular}{|c|c|c|}
\hline $\begin{array}{l}\text { Phage feed at } 1 \times 10^{7} \mathrm{PFU} / \mathrm{ml} \\
\text { via drinking water for } 20 \mathrm{~d}\end{array}$ & $\begin{array}{l}\text { E. coli } \\
\text { CFU } / \mathrm{mL}\end{array}$ & $\begin{array}{l}\text { Mean LR } \\
\left(\log _{10} \text { CFU/ml) }\right.\end{array}$ \\
\hline Time zero (control) & $6 \times 10^{4}$ & - \\
\hline Day 1 & $4 \times 10^{4}$ & $0.17 \pm 0.02$ \\
\hline Day 2 & $2 \times 10^{4}$ & $0.47 \pm 0.03$ \\
\hline Day 3 & $2 \times 10^{4}$ & $0.47 \pm 0.02$ \\
\hline Day 4 & $1 \times 10^{3}$ & $1.78 \pm 0.18$ \\
\hline Day 5 & $1 \times 10^{3}$ & $1.78 \pm 0.09$ \\
\hline Day 6 & $2 \times 10^{3}$ & $1.47 \pm 0.1$ \\
\hline Day 7 & $1 \times 10^{2}$ & $2.78 \pm 0.14$ \\
\hline Day 8 & $2 \times 10^{2}$ & $2.47 \pm 0.22$ \\
\hline Day 10 & $1 \times 10^{3}$ & $1.78 \pm 0.12$ \\
\hline Day 12 & $1 \times 10^{3}$ & $1.78 \pm 0.15$ \\
\hline Day 14 & $1 \times 10^{4}$ & $0.78 \pm 0.08$ \\
\hline Day 16 & $2 \times 10^{3}$ & $1.47 \pm 0.11$ \\
\hline Day 20 & $3 \times 10^{4}$ & $0.3 \pm 0.03$ \\
\hline
\end{tabular}

phage feeding via water drinking. Rat animals were injected orally with phage suspension three times a day. It was found that the baseline $E$. coli output prior to phage feeding was $2.3 \times 10^{5} \mathrm{CFU} / \mathrm{ml}$, noticeable decline started after day 2 and the lowest E. coli count was found in days 6 to 10 , peak of decline was at $6^{\text {th }}$ day, $4 \times 10^{3} \mathrm{CFU} / \mathrm{ml}$ when the maximal phage-driven LR of intestinal E. coli was $1.76 \log$ units. At day 12, E. coli output started to rise again till reaching $1.2 \times 10^{5} \mathrm{CFU} / \mathrm{ml}$ at day 20 (Table 5).

\section{Phage feeding via oral capsules}

In this method of administration, one protocol was pursued which is the continuous feeding. It was found that the baseline $\mathrm{E}$.coli output prior to phage feeding was $1.8 \times 10^{5} \mathrm{CFU} / \mathrm{ml}$. The decline of $E$. coli count was maximal in days 3 to 10 ; peak of decline was at $6^{\text {th }}$ day, $1.7 \times 10^{2} \mathrm{CFU} / \mathrm{ml}$ when the phage-driven LR of intestinal E. coli was $3.02 \log$ units. At day 12, E. coli count started to rise again reaching $2.3 \times 10^{4} \mathrm{CFU} / \mathrm{ml}$. (Table 6).

\section{Group B (rats preloaded with human pathogenic E. coli)}

This group of rat animals was fed continuously for $20 \mathrm{~d}$ with heavily contaminated 60 human pathogenic isolates. At the same time, 140 of corresponding lytic bred phages were given via drinking water, oral injection, and phagecontaining capsules continuously for $20 \mathrm{~d}$.

\section{Baseline fecal output of $E$. coli in group B rats before phage feeding (pretreatment)}

There was a need to monitor the baseline level of $E$. coli output in group B rats that were continuously

Table 5 LR of $E$. coli fecal output due to the effect of continuous feeding of phage master mix for $\mathbf{2 0 ~ d}$ via oral injection with alkali

\begin{tabular}{|c|c|c|}
\hline $\begin{array}{l}\text { Phage feed at } 1 \times 10^{7} \mathrm{PFU} / \mathrm{ml} \\
\text { via oral injection of phages for } 20 \mathrm{~d}\end{array}$ & $\begin{array}{l}\text { E. coli } \\
\text { CFU/mL }\end{array}$ & $\begin{array}{l}\text { Mean LR } \\
\left(\log _{10} \text { CFU/ml) }\right.\end{array}$ \\
\hline Time zero (control) & $2.3 \times 10^{5}$ & - \\
\hline Day 1 & $1.6 \times 10^{5}$ & $0.15 \pm 0.03$ \\
\hline Day 2 & $9 \times 10^{4}$ & $0.4 \pm 0.02$ \\
\hline Day 3 & $1 \times 10^{5}$ & $0.36 \pm 0.07$ \\
\hline Day 4 & $1 \times 10^{4}$ & $1.36 \pm 0.15$ \\
\hline Day 5 & $1 \times 10^{5}$ & $0.36 \pm 0.09$ \\
\hline Day 6 & $4 \times 10^{3}$ & $1.76 \pm 0.18$ \\
\hline Day 7 & $7 \times 10^{3}$ & $1.51 \pm 0.22$ \\
\hline Day 8 & $9 \times 10^{3}$ & $1.4 \pm 0.13$ \\
\hline Day 10 & $8 \times 10^{3}$ & $1.45 \pm 0.1$ \\
\hline Day 12 & $1 \times 10^{5}$ & $0.36 \pm 0.05$ \\
\hline Day 14 & $5 \times 10^{4}$ & $0.66 \pm 0.03$ \\
\hline Day 16 & $5 \times 10^{4}$ & $0.66 \pm 0.06$ \\
\hline Day 20 & $1.2 \times 10^{5}$ & $0.28 \pm 0.04$ \\
\hline
\end{tabular}


Table 6 LR of $E$. coli fecal output due to the effect of continuous feeding of phage master mix for $\mathbf{2 0} \mathrm{d}$ via oral administration of phage-containing capsules

\begin{tabular}{lll}
\hline $\begin{array}{l}\text { Phage feed at } \mathbf{1 \times 1 0 ^ { 6 }} \mathbf{P F U} / \mathbf{m l} \text { via } \\
\text { phage-containing capsules for } \mathbf{2 0 ~ d}\end{array}$ & $\begin{array}{l}\text { E. coli } \\
\text { CFU/mL }\end{array}$ & $\begin{array}{l}\text { Mean LR } \\
\left(\log _{\mathbf{1 0}} \text { CFU/ml) }\right.\end{array}$ \\
\hline Time zero (control) & $1.8 \times 10^{5}$ & - \\
Day 1 & $1.1 \times 10^{5}$ & $0.21 \pm 0.04$ \\
Day 2 & $9 \times 10^{3}$ & $1.3 \pm 0.15$ \\
Day 3 & $1 \times 10^{3}$ & $2.25 \pm 0.07$ \\
Day 4 & $8 \times 10^{3}$ & $1.35 \pm 0.2$ \\
Day 5 & $7.6 \times 10^{2}$ & $2.37 \pm 0.16$ \\
Day 6 & $1.7 \times 10^{2}$ & $3.02 \pm 0.22$ \\
Day 7 & $2.8 \times 10^{2}$ & $2.8 \pm 0.18$ \\
Day 8 & $1 \times 10^{3}$ & $2.25 \pm 0.24$ \\
Day 10 & $8.5 \times 10^{3}$ & $1.32 \pm 0.1$ \\
Day 12 & $2.3 \times 10^{4}$ & $0.89 \pm 0.07$ \\
Day 14 & $1 \times 10^{4}$ & $1.25 \pm 0.1$ \\
Day 16 & $1 \times 10^{5}$ & $0.25 \pm 0.05$ \\
Day 20 & $2 \times 10^{5}$ & $-0.04 \pm 0.006$ \\
\hline
\end{tabular}

administered a contaminated, $10^{8} \mathrm{CFU} / \mathrm{mL}$, drinking water orally without phage cocktail feed. After loading up rat intestines with human pathogenic E. coli, it was found that $E$. coli output at day 0 was $2.1 \times$ $10^{5} \mathrm{CFU} / \mathrm{ml}$ and $E$. coli count started to increase after $24 \mathrm{~h}$, peak of increase was at day $6,1.1 \times 10^{7} \mathrm{CFU} / \mathrm{ml}$ or $1.71 \mathrm{log}$ units. Then, fecal output of $E$. coli started to decline reaching $3.4 \times 10^{5} \mathrm{CFU} / \mathrm{ml}$ at day 20 (Table 7).

Table 7 Fecal output of $E$. coli increased with the effect of continuous human pathogenic $E$. coli feeding for $20 \mathrm{~d}$ via drinking water

\begin{tabular}{|c|c|}
\hline $\begin{array}{l}\text { Pathogenic } E \text {. coli feed at } 1 \times 10^{8} \\
\text { CFU } / \mathrm{ml} \text { with water drink for } 20 \mathrm{~d}\end{array}$ & $\begin{array}{l}\text { Total E. coli output } \\
\text { count (CFU/ml) }\end{array}$ \\
\hline Time zero & $2.1 \times 10^{5}$ \\
\hline Day 1 & $2.4 \times 10^{5}$ \\
\hline Day 2 & $3.2 \times 10^{6}$ \\
\hline Day 3 & $7 \times 10^{6}$ \\
\hline Day 4 & $6.3 \times 10^{6}$ \\
\hline Day 5 & $8.5 \times 10^{6}$ \\
\hline Day 6 & $1.1 \times 10^{7}$ \\
\hline Day 7 & $1 \times 10^{7}$ \\
\hline Day 8 & $9 \times 10^{6}$ \\
\hline Day 10 & $8.7 \times 10^{5}$ \\
\hline Day 12 & $7 \times 10^{5}$ \\
\hline Day 14 & $5.3 \times 10^{5}$ \\
\hline Day 16 & $5.1 \times 10^{4}$ \\
\hline Day 20 & $3.4 \times 10^{5}$ \\
\hline
\end{tabular}

\section{Phage feeding via drinking water}

Rats that were already fed with heavily contaminated $60 \mathrm{E}$. coli pathogens, were fed with the phage master mix in separate feeding bottle simultaneously for $20 \mathrm{~d}$. Since the protocol of phage feeding with alkali for $20 \mathrm{~d}$ was shown as the best in group A rats, it was the only drinking protocol pursued in group B rats. It was intended to monitor is there any decline of the total $E$. coli output when the pathogenic $E$. coli-inoculated rats were fed with the specific phages of the inoculated pathogens. And whether phage feeding is able to stop or reverse the $E$. coli output upsurge. It was found that phage feeding succeeded in reversing the upsurge of total E. coli output starting from day 2 and severe lowering of $E$. coli output was peaked in days 5 to 8; peak lowering was in day $7,8.2 \times 10^{2} \mathrm{CFU} / \mathrm{ml}$, when the $E$. coli level in the pre-treatment rats was $1 \times 10^{7} \mathrm{CFU} / \mathrm{ml}$. Therefore, the expected phage-driven LR of E. coli output was the difference between the E. coli output in group B rats without phage feeding, $1 \times 10^{7} \mathrm{CFU} / \mathrm{ml}$, and that seen in group B rats with phage feeding, $8.2 \times 10^{2} \mathrm{CFU} / \mathrm{m}$, namely $4.07 \log$ units. After day 10 , the E. coli output started to rise again reaching $4.6 \times 10^{5} \mathrm{CFU} / \mathrm{ml}$ (Table 8).

\section{Phage feeding via oral injection}

Phage feeding was conducted by oral injections of lambda buffer solution with $6 \% \mathrm{w} / \mathrm{v}$ Sodium bicarbonate (alkali) thrice a day for $20 \mathrm{~d}$. It was found that results were relatively similar but a bit less prominent than that of water drinking protocol done for group B rats. The lowering in E. coli output was started in day 2; peaked in days 5-8. The maximal LR was at day 7, $3.45 \log$ units (Table 9).

Table $8 \mathrm{E}$. coli output decline in group B rats due to the continuous phage feeding for $\mathbf{2 0} \mathrm{d}$ via water drinking with alkali

\begin{tabular}{|c|c|c|}
\hline $\begin{array}{l}\text { Phage feed at } 1 \times 10^{7} \mathrm{PFU} / \mathrm{ml} \\
\text { via drinking water for } 20 \mathrm{~d}\end{array}$ & $\begin{array}{l}\text { Total E. coli output } \\
\text { count }(\mathrm{CFU} / \mathrm{mL})\end{array}$ & $\begin{array}{l}\text { Mean LR } \\
\left(\log _{10} \text { CFU/ml) }\right.\end{array}$ \\
\hline Time zero & $1.4 \times 10^{5}$ & - \\
\hline Day 1 & $1.9 \times 10^{5}$ & $0.1 \pm 0.03$ \\
\hline Day 2 & $3.5 \times 10^{5}$ & $0.96 \pm 0.09$ \\
\hline Day 3 & $4.1 \times 10^{5}$ & $1.23 \pm 0.13$ \\
\hline Day 4 & $7.4 \times 10^{4}$ & $1.93 \pm 0.11$ \\
\hline Day 5 & $6.8 \times 10^{3}$ & $3.09 \pm 0.28$ \\
\hline Day 6 & $5.2 \times 10^{3}$ & $3.32 \pm 0.24$ \\
\hline Day 7 & $8.2 \times 10^{2}$ & $4.08 \pm 0.3$ \\
\hline Day 8 & $8.7 \times 10^{2}$ & $4.01 \pm 0.23$ \\
\hline Day 10 & $4 \times 10^{3}$ & $2.33 \pm 0.16$ \\
\hline Day 12 & $6.3 \times 10^{3}$ & $2.04 \pm 0.14$ \\
\hline Day 14 & $3 \times 10^{4}$ & $1.24 \pm 0.1$ \\
\hline Day 16 & $5.7 \times 10^{5}$ & $-1.04 \pm 0.06$ \\
\hline Day 20 & $3 \times 10^{5}$ & $0.05 \pm 0.002$ \\
\hline
\end{tabular}


Table 9 E. coli output decline due to the continuous phage feeding for $20 \mathrm{~d}$ via oral injection of group $B$ rats

\begin{tabular}{|c|c|c|}
\hline $\begin{array}{l}\text { Phage feed at } 1 \times 10^{7} \mathrm{PFU} / \mathrm{ml} \\
\text { via oral injection for } 20\end{array}$ & $\begin{array}{l}\text { Total E. coli output } \\
\text { count (CFU/mL) }\end{array}$ & $\begin{array}{l}\text { Mean LR } \\
\left(\log _{10} \mathrm{CFU} / \mathrm{ml}\right)\end{array}$ \\
\hline Time zero (control -ve) & $2.4 \times 10^{6}$ & - \\
\hline Day 1 & $2.3 \times 10^{5}$ & $0.01 \pm 0.003$ \\
\hline Day 2 & $2.5 \times 10^{5}$ & $1.1 \pm 0.08$ \\
\hline Day 3 & $3.2 \times 10^{5}$ & $1.33 \pm 0.12$ \\
\hline Day 4 & $7.3 \times 10^{4}$ & $1.9 \pm 0.14$ \\
\hline Day 5 & $4.2 \times 10^{4}$ & $2.3 \pm 0.09$ \\
\hline Day 6 & $8.4 \times 10^{3}$ & $3.1 \pm 0.24$ \\
\hline Day 7 & $3.5 \times 10^{3}$ & $3.45 \pm 0.2$ \\
\hline Day 8 & $8.1 \times 10^{3}$ & $3.04 \pm 0.3$ \\
\hline Day 10 & $5.8 \times 10^{3}$ & $2.17 \pm 0.17$ \\
\hline Day 12 & $7.1 \times 10^{4}$ & $0.99 \pm 0.1$ \\
\hline Day 14 & $2 \times 10^{5}$ & $0.42 \pm 0.07$ \\
\hline Day 16 & $7 \times 10^{4}$ & $-0.13 \pm 0.02$ \\
\hline Day 20 & $3 \times 10^{5}$ & $0.054 \pm 0.006$ \\
\hline
\end{tabular}

\section{Phage feeding via oral capsules}

Phage feeding was conducted by administering phagecontaining capsules thrice a day for 20 days. It was found that the lowering in E. coli output was started in day 2; peaked in days $5-8$. The maximal lowering was in day 6 , $2.6 \times 10^{2} \mathrm{CFU} / \mathrm{ml}$ and the peak LR was $4.62 \mathrm{log}$ units. E. coli output then started to increase after day 10 reaching $5.3 \times 10^{5} \mathrm{CFU} / \mathrm{ml}$ at day 20 (Table 10 ).

\section{Phage shedding during phage feeding}

It was found that phage shedding increased gradually after day 1 and peaked in days 4-12 then it declined

Table 10 E. coli output decline due to the continuous phage feeding for $\mathbf{2 0} \mathrm{d}$ via phage-containing capsules

\begin{tabular}{lll}
\hline $\begin{array}{l}\text { Phage feed at } \mathbf{1 \times 1 0 ^ { 6 }} \mathbf{P F U} / \mathbf{m l} \\
\text { in vegetable capsules for } \mathbf{2 0} \mathbf{~ d}\end{array}$ & $\begin{array}{l}\text { Total E. coli output } \\
\text { count }(\mathrm{CFU} / \mathbf{m l})\end{array}$ & $\begin{array}{l}\text { Mean LR } \\
\left(\mathbf{l o g}_{10} \text { CFU/ml) }\right.\end{array}$ \\
\hline Time zero (control-ve) & $3.1 \times 10^{6}$ & - \\
Day 1 & $3.7 \times 10^{6}$ & $-1.18 \pm 0.07$ \\
Day 2 & $6.2 \times 10^{5}$ & $0.71 \pm 0.05$ \\
Day 3 & $9 \times 10^{4}$ & $1.89 \pm 0.13$ \\
Day 4 & $2.8 \times 10^{4}$ & $2.35 \pm 0.21$ \\
Day 5 & $3.2 \times 10^{3}$ & $3.42 \pm 0.026$ \\
Day 6 & $2.6 \times 10^{2}$ & $4.62 \pm 0.32$ \\
Day 7 & $3.7 \times 10^{2}$ & $4.43 \pm 0.028$ \\
Day 8 & $6.9 \times 10^{2}$ & $4.1 \pm 0.17$ \\
Day 10 & $7.3 \times 10^{3}$ & $2.07 \pm 0.09$ \\
Day 12 & $4.8 \times 10^{4}$ & $1.16 \pm 0.14$ \\
Day 14 & $2.3 \times 10^{5}$ & $0.36 \pm 0.05$ \\
Day 16 & $4.4 \times 10^{5}$ & $-0.93 \pm 0.1$ \\
Day 20 & $5.3 \times 10^{5}$ & $-0.19 \pm 0.04$ \\
\hline
\end{tabular}

again which is the reverse pattern seen for E. coli output. There was no remarkable difference between the pattern of phage shedding between oral injection and phage-containing water drink (Table 11).

Escherichia coli O157 and other EHEC are believed to be carried asymptomatically by cattle, cows and sheep [5]. Shedding of the organism in the faeces of animals is intermittent and can be exacerbated by a variety of factors [21] including stress and feed types. Therefore, a thorough approach is needed to control the microbial load of the pathogenic E. coli where bovine and other warm-blooded animal's feacal contamination is possible. The ability of phages to recognize precisely their hosts rendered the use of phages as antibacterial agents favorable because of the fact that broad-spectrum antibiotics kill the target bacteria along with all beneficial bacteria in the farm or in the organism body [10].

Unfortunately this was the bright side of the story; on the other hand, phage specificity imposed a complicated dilemma, which is the difficulty of finding sufficient phage strains which could cover all or most of bacterial host strains. Thus, the inability to cover all strains of certain bacterial species along with the easy development of evolutionary resistance by the bacteria against their phages, have made phage therapy or biocontrol is unsuccessful [15]. This was worked out by the novel techniques of phage breeding and optimization pursued by our team [IPO-UK Patent Application No. 0822068]. This prepared the suitable background for formulating highly lytic and optimized cocktail of large number of anti- $E$. coli phages that are able to apply predator effect on hundreds of target bacteria. For this reason, phage cocktail

Table 11 Phage shedding from the studied rats during phage feeding biocontrol

\begin{tabular}{|c|c|c|}
\hline $\begin{array}{l}\text { Phage feed at } 1 \times 10^{7} \\
\text { PFU/ml with water drink } \\
\text { and oral injection for } 20 \mathrm{~d}\end{array}$ & $\begin{array}{l}\text { Total phage } \\
\text { shedding (PFU/ml) } \\
\text { via water drink }\end{array}$ & $\begin{array}{l}\text { Total phage } \\
\text { shedding (PFU/ml) } \\
\text { via oral injection }\end{array}$ \\
\hline Time zero (control -ve) & 0 & 0 \\
\hline Day 1 & 0 & 40 \\
\hline Day 2 & $1.18 \times 10^{3}$ & $8.0 \times 10^{2}$ \\
\hline Day 3 & $1.22 \times 10^{3}$ & $9.4 \times 10^{2}$ \\
\hline Day 4 & $2.6 \times 10^{4}$ & $1.2 \times 10^{3}$ \\
\hline Day 5 & $8.3 \times 10^{4}$ & $5.2 \times 10^{3}$ \\
\hline Day 6 & $2.7 \times 10^{5}$ & $3.8 \times 10^{4}$ \\
\hline Day 7 & $5.4 \times 10^{5}$ & $4.1 \times 10^{5}$ \\
\hline Day 8 & $1.5 \times 10^{4}$ & $7.9 \times 10^{4}$ \\
\hline Day 10 & $3.7 \times 10^{3}$ & $3.8 \times 10^{3}$ \\
\hline Day 12 & $7.2 \times 10^{2}$ & $8.7 \times 10^{2}$ \\
\hline Day 14 & $1.1 \times 10^{2}$ & 64 \\
\hline Day 16 & 8.9 & 6 \\
\hline Day 20 & 0 & 0 \\
\hline
\end{tabular}


of anti- E. coli bacteria, the phage master mix, was used to control and predate target strains of $E$. coli whether reside naturally inside rat animals or artificially inoculated human pathogenic $E$. coli in rat guts. The aim of this was to evaluate the capability of phage cocktail to suppress the microbial load of $E$. coli represented by the reduction in $E$. coli fecal output. This has special importance because most cases of transmission of pathogenic E. coli including O157:H7 are related to fecal contamination by animals to the food chain [22]. Therefore, it was conceived that decreasing or abolishing the fecal contamination would decrease largely the chances for human beings to contract $E$. coli infection.

Accordingly, in the current study, it was found that the used phage cocktail was remarkably successful in lowering the E. coli output of both E. coli flora and externally inoculated pathogenic $E$. coli bacteria in significant manner. Three protocols were used of phage feeding via drinking, phage feeding for one day, for 20 $\mathrm{d}$, and $20 \mathrm{~d}$ with alkali. It was found that single day phage feed was effective but much less efficient than continuous phage feed for $20 \mathrm{~d}$ with or without alkali. In single day feed, brief $E$. coli decline for 3 days, $4^{\text {th }}$ to $6^{\text {th }}$ day and maximal LR was $1.22 \log$ units and then at $7^{\text {th }}$ day $E$. coli output began to rise again due to the loss of the phage lysing effect. In $20 \mathrm{~d}$ phage feed, the decline of $E$. coli load began after 3 days with extended lowering phase ranged from $5^{\text {th }}$ days to $10^{\text {th }}$ day and the maximal LR was $2.3 \mathrm{log}$ units without alkali and 2.78 with alkali. The difference in LR of $E$. coli between single day and $20 \mathrm{~d}$ continuous feed was remarkable, $1.56 \mathrm{log}$ units. This indicated that there was a remarkable enhancement in phage-driven $E$. coli control by using daily phage feed rather than one or few days feeding. Moreover, there was another little enhancement when alkali was used which could counteract the acidity of rats' stomach.

On the other hand, using continuous phage feed by oral injection of phages-containing lambda buffer with alkali did not give better results as was expected. The oral injection of phages resulted in $1.02 \log$ units less LR than that of continuous phage feed via drinking water. This might be attributed to the frequency of the oral injections of phages into rats per day. Rats were orally injected thrice a day and this most probably was less effective than the available phage-containing drinking water given that rats drink water, roughly, every 10-15 min which guarantees undisrupted supply of the phage cocktail. However, it is expected that more frequent oral injections of phages per day might lead to much better results. However, the current study provided evidence that oral injection of phages is not a practicable option as injecting phages orally needs much efforts and equipment. On the contrary, feeding phages, at $10^{6} \mathrm{PFU} / \mathrm{ml}$, via vegetable capsules proved to be superior. Phage containing capsules administered 3 times a day succeeded to achieve $L R>3$ $\log$ units, 3.02, while other routes of demonstration did not. This might be attributed to the better protection of phages from stomach acidity than using alkali.

For group B rats, human pathogenic E. coli were fed to rat animals in parallel with administering specific coliphage cocktail in order to measure the potential of the phage master mix in controlling the externally inoculated pathogenic $E$. coli as well as the resident E. coli flora of rats. Rats fed with heavy dose of human pathogenic $E$. coli tolerated well these bacteria in that a remarkable increase was seen in the total E. coli output after feeding $10^{8} \mathrm{CFU} / \mathrm{ml}$ of $E$. coli daily for $20 \mathrm{~d}$. After just $6 \mathrm{~d}$ of the inoculation of the pathogenic $E$. coli, the fecal output of $E$. coli was $1.8 \log$ units higher than before; $E$. coli output increased after 4 to $10 \mathrm{~d}$ and this upsurge of $E$. coli was then started to decline progressively. Similar to the behavior of the introduced phages, it is prudent to think that the mucosal immunity of rats' gut was responsible for this lowering of E. coli upsurge. However, our hypothesis is that if rat animals, which were already loaded with external $E$. coli, were challenged with phage feeding specific to the same collection of external $E$. coli, then $E$. coli output upsurge should start to decline before the immunity develops, before $10^{\text {th }}$ day, just like the case for the group A rats when the natural $E$. coli flora was challenged by phage feeding. A striking $E$. coli output lowering was achieved by phage feed for $20 \mathrm{~d}$ with alkali via water drink, oral injection of phage containing lambda buffer, and phage containing capsules. The fecal output of $E$. coli did not increase in rats received phages concomitantly with pathogenic E. coli. Moreover, there was huge lowering of $E$. coli output mainly after five to eight d from phage-bacteria feeding. The peak LR of fecal output of E. coli was 4.08, 3.45, and $4.62 \log$ units in rats subjected to $20 \mathrm{~d}$ phage feed via drinking water, oral injection, and capsules respectively. Hence, phage feed reversed the upsurge of $E$. coli output. This provided evidence that phage feed biocontrol is more efficient in combating the pathogenic non natural $E$. coli flora than combating natural flora bacteria. Therefore, phage feed proved to be useful in suppressing both animals $E$. coli flora and more efficiently the external $E$. coli pathogens in their intestines.

For more confidence in the phage effect in controlling the residing $\mathrm{E}$.coli inside animals' intestine, phage shedding was explored, it was found that phage shedding peaks with the peak decline of E. coli output and then phage shedding starts to abolish reaching zero at the end of the third week. There was no significant difference between phage shedding in animals fed with phages via water drink or via oral injection. The pattern seen in this study for phage shedding and phage-driven E. coli output control was believed to be immune response -dependent. Rats developed effective immunity 
against all introduced phages as well as introduced human pathogenic E. coli isolates. The developed immune reaction was thought first as $E$. coli resistance against invading phages but in vitro plaque assay of $E$. coli bacteria isolated from fecal output of rats before and after phage feeding showed that $E$. coli bacteria after phage feeding were as sensitive to the fed phages as $E$. coli bacteria isoalted before phage feeding [data not shown]. Therefore, the gradual loss of the phagedriven E. coli control was most likely attributed to immunity development. Moreover, phage shedding pattern confirmed this explanation as introduced phages were eliminated gradually at the same period of introduced bacteria elimination. In addition, it is noteworthy to mention that some rat animals that were used in phage feeding two month earlier were rechallenged again with the same phage cocktail. The phage biocontrol was null even two months passed since last time phage feeding was done [data not shown]. This finding was another proof for the immunity hypothesis for the termination of the phage feeding effect control.

In recent years, there has been an obsessive question, whether phages are safe for use in biocontrol or therapy. No signs or symptoms were found when phage cocktail was given. It was cautioned that high number of phages introduced into rat guts might lead to extensive abolishment of $E$. coli flora; but, fortunately, it was found that E. coli load was lowered but not abolished completely in a way that no signs and symptoms of disturbance in bowel habit was noticed nor any other change of animals behavior was observed. This was a clue on the harmless use of phages for lowering E. coli load in animals. Given that such phage-based biocontrol is conducted only six to eight days before animal slaughter, say cattle, hence, longterm adverse effects of using phages might be zero. The safety of phages was assured by Duckworth and Gulig [23] who stated that there has been no evidence that exposure to phage particles, even ones normally associated with disease-causing bacteria, can actually result in the occurrence of human disease. In addition, the recent FDA approval of Listeria-specific bacteriophage preparations for food preservation has opened the door to new applications of these natural bacterial killers taken that bacteriophages are viruses that only infect and lyse bacterial cells and are harmless to mammalians [24]. Another safety aspect might be taken into consideration, phages replicate at the site of infection or wherever the host bacteria are present while phages are absent in sterile areas ensuring an optimal self-adjusting dose of phages which is not found in other modes of non-biological antimicrobial agents [25].

\section{Conclusions}

Taken together, it was concluded that phage feed as a mean of biocontrol for lowering the microbial load of E. coli bacteria inside animals' intestine proved to be successful. The suppression of $E$. coli output reached 3 $\log$ units for rats intestine resident E. coli and $4.62 \mathrm{log}$ units for both externally inoculated and flora $E$. coli. And phage feeding using phage cocktail composed of high number, 140, of specific bred phages coliphages ensured the wide coverage of $E$. coli strains and substrains leading to efficient $E$. coli load suppression. Moreover, the best administration route of phage cocktail was found to be via vegetables capsules followed by drinking water which were more efficient that injecting phages directly into rat throat. In addition, phage cocktail fed continuously for $20 \mathrm{~d}$ was the best protocol of feeding and better to be accompanied by a small percentage of biologically safe alkali such as Sodium bicarbonate that resulted in better phage control. The pattern of the phage-based E. coli biocontrol highlighted that timing of the preharvest animal biocontrol is the most critical step deciding the success of the phage biocontrol. It was concluded that the $6^{\text {th }}, 7^{\text {th }}$, and $8^{\text {th }}$ days after the beginning of the phage feeding were the best days to slaughter the animal when the highest phage shedding and the lowest E. coli output were seen. Even though $6^{\text {th }}$ or $7^{\text {th }}$ day might be better than $8^{\text {th }}$ day, it is preferred to do slaughtering in the $8^{\text {th }}$ day to allow 2 days of minimal $E$. coli output before slaughtering. This can ensure that $E$. coli contamination into the food chain will be greatly minimized.

\section{Competing interests}

Authors confirm that there is no conflict of interests of any kind.

\section{Authors' contributions}

AS designed and conducted the research, SAAJ and F designed the research. All authors read and approved the final manuscript.

\section{Acknowledgements}

Thanks to Rawafid and ABC companies for their fund and support. Appreciation for the University Putra Malaysia for incubating this research.

\section{Author details}

${ }^{1}$ Microbiology Department, College of Medicine, Alnahrain University, Baghdad 14222, Iraq. ${ }^{2}$ Applied Bio Research Inc., 455 Pelissier St., Windsor, Ontario N9A 6Z9, Canada. ${ }^{3}$ Faculty of Food Science, University Putra Malaysia, Serdang 43400, Selangor, Malaysia.

Received: 9 May 2014 Accepted: 19 July 2014 Published: 26 July 2014

\section{References}

1. Kaper JB, Nataro JP, Mobley HLT: Pathogenic Escherichia coli. Nat Rev Microbiol 2004, 2:123-140.

2. Carone BR, Xu T, Murphy KC, Marinus MG: High incidence of multiple antibiotic resistant cells in cultures of in enterohemorrhagic Escherichia coli 0157:H7. Mutat Res 2014, 759:1-8.

3. Wall PG, McDonnell RJ, Adak GK, Cheasty T, Smith HR, Rowe B: General outbreaks of vero cytotoxin producing Escherichia coli 0157 in England and Wales from 1992 to 1994. Commun Dis Rep CDR Rev 1996, 6:26-33.

4. Hawker J, Begg NB, Blair B, Reintjes R, Weinberg J: Communicable Disease Control Handbook. Oxford: Blackwell; 2001. 
5. Rasmussen MA, Casey TA: Environmental and food safety aspects of Escherichia coli 0157:H7 infections in cattle. Crit Rev Microbiol 2001, 27:57-73.

6. Hussein HS: Prevalence and pathogenicity of Shiga toxin-producing Escherichia coli in beef cattle and their products. J Anim Sci 2007, 85:E63-E72.

7. Yoder JS, Blackburn BG, Craun GF, Hill V, Levy DA, Chen N, Lee SH, Calderon RL, Beach MJ: Surveillance for waterborne-disease outbreaks associated with recreational water-United States. MMWR Surveill Summ 2004, 53:1-22

8. Grandgirard D, Loeffler JM, Fischetti VA, Leib SL: Phage lytic enzyme Cpl-1 for antibacterial therapy in experimental pneumococcal meningitis. $J$ Infect Dis 2008, 197:1519-1522.

9. Rea MC, Alemayehu D, Ross RP, Hill C: Gut solutions to a gut problem: bacteriocins, probiotics and bacteriophage for control of Clostridium difficile infection. J Med Microbiol 2013, 62(Pt 9):1369-1378.

10. Merril CR, Scholl D, Adhya SL: The prospect for Bacteriophage therapy in Western medicine. Nat Rev Drug Discov 2003, 2:489-497.

11. Wittebole X, De Roock S, Opal SM: A historical overview of bacteriophage therapy as an alternative to antibiotics for the treatment of bacterial pathogens. Virulence 2014, 5(1):226-235.

12. Barrow PA, Soothill JS: Bacteriophage therapy and prophylaxis: rediscovery and renewed assessment of potential. Trends Genet 1997, 5:268-271.

13. Carlton RM: Phage therapy: past history and future prospects. Arch Immunol Ther Exp 1999, 47:267-274.

14. Verbeken G, Pirnay JP, De Vos D, Jennes S, Zizi M, Lavigne R, Casteels M, Huys I: Optimizing the European regulatory framework for sustainable bacteriophage therapy in human medicine. Arch Immunol Ther Exp (Warsz) 2012, 60(3):161-172.

15. Vieu JF: Les Bacteriophages. In Fraite de Therapeutique. Edited by Fabre J. Paris: Vol. Serums et Vaccins. Flammarion; 1975:337-400.

16. Smith HW, Huggins MB: Effectiveness of phages in treatingexperimental Escherichia coli diarrhoea in calves, piglets and lambs. $J$ Gen Microbiol 1983, 129:2659-2675.

17. Smith HW, Huggins MB, Shaw KM: The control of experimental Escherichia coli diarrhoea in calves by means of bacteriophages. J Gen Microbiol 1987, 133:1111-1126.

18. Tauxe RV: Emerging foodborne diseases: an evolving public health challenge. Emerg Infect Dis 1997, 3:425-434.

19. Topley WWC, Wilson GS: Principles of bacteriology, virology and immunity. London, United Kingdom: B.C. Decker Publisher; 1990

20. Drake D: Assessment of antimicrobial activity against biofilms. In Microbial growth in biofilms vol. 2. Edited by Doyle RJ. London, UK: Academic press; 2001:373-375.

21. Garber L, Wells S, Shroeder-tucker L: Factors associated with the faecal shedding of verotoxin-producing Escherichia coli 0157 on dairy farms. J Food Prot 1999, 62:307-312.

22. Callaway TR, Anderson RC, Edrington TS, Genovese KJ, Bischoff KM, Poole TL, Jung YS, Harvey RB, Nisbet DJ: What are we doing about Escherichia coli 0157:H7 in cattle? J Anim Sci 2004, 82(E-Suppl):E93-E99.

23. Duckworth DH, Gulig PA: Bacteriophages: potential treatment for bacterial infections. BioDrugs 2002, 16:57-62.

24. Chibeu A, Agius L, Gao A, Sabour PM, Kropinski AM, Balamurugan S: Efficacy of bacteriophage LISTEXP100 combined with chemical antimicrobials in reducing Listeria monocytogenes in cooked turkey and roast beef. Int J Food Microbiol 2013, 167(2):208-214.

25. Drilling A, Morales S, Boase S, Jervis-Bardy J, James C, Jardeleza C, Tan NC, Cleland E, Speck P, Vreugde S, Wormald PJ: Safety and efficacy of topical bacteriophage and ethylenediaminetetraacetic acid treatment of Staphylococcus aureus infection in a sheep model of sinusitis. Int Forum Allergy Rhinol 2014, 4(3):176-186.

doi:10.1186/s12941-014-0039-z

Cite this article as: Abdulamir et al: Novel approach of using a cocktail of designed bacteriophages against gut pathogenic $E$. coli for bacterial load biocontrol. Annals of Clinical Microbiology and Antimicrobials 2014 13:39

\section{Submit your next manuscript to BioMed Central and take full advantage of:}

- Convenient online submission

- Thorough peer review

- No space constraints or color figure charges

- Immediate publication on acceptance

- Inclusion in PubMed, CAS, Scopus and Google Scholar

- Research which is freely available for redistribution

Submit your manuscript at www.biomedcentral.com/submit
C Biomed Central 